\title{
Efek Psikologi Manipulasi Elemen Air dalam Desain Interior - Studi Kasus : Fitur Air Jatuh Dengan Pengaturan Rendah
}

\author{
I Ketut Suarna ${ }^{(1)}$ \\ (1)Staf Pengajar, Program Studi Desain Interior ITSB. suarnatp@gmail.com
}

\begin{abstract}
Abstrak
Manipulasi elemen air dalam desain interior memberi gambaran bahwa manusia membutuhkan stimulus dalam merestorasi prilakunya. Melalui eksperimen 3 model fitur air dengan kategori volume tumpahan besar, medium dan kecil, penelitian ditujukan untuk mencari fitur mana yang cenderung lebih efektik memberi dampak psikologi yang lebih baik. Suara yang dihasilkan dari ketiga model fitur air direkam dan diolah dengan software Audacity untuk dijadikan stimulus melalui uji listening kepada 30 responden. Dampak psikologi yang ditimbulkan diukur melalui penilaian terhadap respon persepsi dan respon emosi melalui kuisioner yang disusun dengan metoda semantik diferensial. Pengukuran respon persepsi dikaitkan dengan atribut fisik berupa kualitas bunyi air (ketajaman, kasar-halus, kecepatan yang dikaitkan dengan deras atau pelan) dan variasi bunyi yang yang dikaitkan dengan konstan atau bervariasinya bunyi. Sementara penilaian terhadap respon emosi dikaitkan dengan dampak ketenangan, rileks, alami, familiar, kesegaran, senang dan tegang. Fitur air yang cenderung mendapat penilaian positf adalah fitur dengan bentuk tumpahan satu titik sebagai perwakilan volume tumpahan yang kecil.
\end{abstract}

Kata kunci : manipulasi air, desain interior, psikologi, persepsi, emosi

\begin{abstract}
Manipulation of water elements in interior design illustrates that humans need a stimulus in restoring their behavior. Through the experiment of 3 water feature models with large, medium and small volume spill volumes, the research is aimed to find which features tend to be more effective and have a better psychological impact. The sound produced from the three water feature models was recorded and processed with Audacity software to be used as a stimulus through a listening test to 30 respondents. The psychological impact caused is measured through the assessment of perception responses and emotional responses through questionnaires compiled by differential semantic methods. Measurement of perception response is associated with physical attributes in the form of water sound quality (sharpness, rough-smooth, the speed associated with heavy or slow and variations in sound associated with constant or varying sounds. While the assessment of emotional responses is associated with the effects of calm, relaxed, natural, familiar, fresh, happy and tense. Water features that tend to get positive ratings are features with a single spill shape as a representative volume of small spills.
\end{abstract}

Keywords: water manipulation, interior design, psychology, perception, emotions

\section{Pengantar}

Manusia merupakan subyek perancangan dalam konteks "meruang manusiawi". Tuntutan dan kebutuhan fisik dan psikisnya menjadi pertimbangan penting dalam setiap tahap perancangan. Secara fisik, ruang memiliki elemen-elemen yang keberadaannya jelas dan terukur secara visual, memberi batas teritorial, serta menjadi pemisah aktifitas yang berbeda. Selanjutnya secara psikis manusia dipengaruhi persepsi sebagai respon terhadap kondisi lingkungan yang ditempati.

Keberadaaan warna, garis, bidang, tekstur, pemilihan material tertentu, proporsi, komposisi dan berbagai elemen desain akan membangkitkan respon yang berbeda pada setiap individu dengan melibatkan multi 
sensorinya. Keterlibatan sensori visual merupakan hal dominan diantara sensori lainnya seperti sensori dengar, penciuman atau sensori sentuh (Hall, 1982). Dalam kaitan membangun persepsi sebagai respon tuntutan psikologi, tidak jarang elemen alam seperti unsur vegetasi dan elemen air menjadi alternatif untuk dihadirkan dalam perancangan ruang binaan.

Keberadaan reflecting pond, berbagai fitur air jatuh, air mancur, ataupun gerakan air mengalir secara horisontal menjadi fenomena umum pada ruang terbuka publik. Sementara dalam desain interior, para praktisi telah melakukan manipulasi elemen air kedalam berbagai bentuk, seperti: akuarium, gravitasi air jatuh di bidang kaca atau batu alam, gemericik air pancuran ataupun air terjun mini.

Minimnya literatur atau penjelasan mengenai dampak yang ditimbulkan dari upaya manipulasi elemen air dalam desain interior menjadi alasan untuk melakukan eksperimen terhadap salah satu fitur, yaitu fitur air jatuh dengan seting yang rendah sebagai salah satu fitur yang dapat di aplikasikan di dalam ruangan. Eksperimen ini ditujukan sebagai upaya dalam menggali potensi pengelolaan karakteristik air, yang secara umum dijabarkan ke dalam 4 bagian (Booth, 1990), yaitu: plasticity, motion, sound, reflectivity. Dari empat karakteristik air, penelitian ini diarah pada karakteristik bunyi air dengan membedakan volume dan bentuk tumpahannya.

\section{Metode}

Penelitian ini merupakan penelitian eksperimen dengan mixed method. Metode kuantitatif dipergunakan dalam pengolahan data yang dimulai dari merekam suara air yang dihasilkan dari masing-masing model untuk dirubah menjadi data melalui sofware matlab sehingga diketahui perbedaan warna dari masing masing model dengan mencatat tekanan suaranya dalam angka. Dengan software audacity, hasil rekaman ini diolah sebagai stimulus dalam uji listening yang responnya dijawab melalui kuisioner dengan metode semantik diferencial, Angka-angka yang diperoleh akan dibandingkan dan diolah dengan software SPSS untuk melihat perbedaan nilai signifikannya. Hasil akhir dari tingkat kecenderungan menjadi simpulan yang dipaparkan secara deskritif (kualitatif).

\subsection{Menyiapkan Stimulus}

Menyiapkan stimulus dimulai dari merencanakan model fitur air yang aplikatif penerapannya dalam ruangan. Seting ketinggian tumpahan dibuat $50 \mathrm{~cm}$ untuk semua fitur air dari permukaan air pada bak penampungnya. Dengan pertimbangan tidak menimbulkan tumpahan atau percikan yang dapat membasahi lantai ataupun furniture yang lain ketika diaplikasikan dalam ruangan. Bentuk dan volume tumpahan dibagi ke dalam 3 kategori, yaitu:

- Kategori I, volume tumpahan besar (tumpahan lebar)

Lebar tumpahan dibuat $40 \mathrm{~cm}$, debit air yang keluar menjadi lebih besar yang menimbulkan Suara lebih deras, dan selanjutnya dalam penelitian ini disebut Kondisi 1
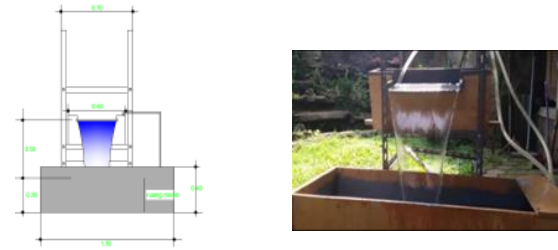

Gambar 1. Kategori I (volume besar)

Sumber: dok.pribadi

- Kategori II, volume tumpahan sedang (bentuk tumpahan beberapa titik)

Terdapat 8 titik lubang berdiameter $0,5 \mathrm{~cm}$ dengan jarak antara lubang satu dengan lubang lainnya $5 \mathrm{~cm}$, suara yang ditimbulkan lebih bervariasi, dan selanjutnya dalam penelitian ini disebut sebagai Kondisi 2

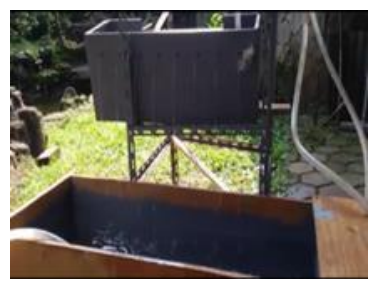

Gambar2. Kategori II (volume sedang), beberapa titik tumpahan

Sumber: dok.pribadi 
- Kategori III, volume kecil (bentuk tumpahan 1 titik )

Tumpahan air berasal dari 1 titik dengan diameter $12 \mathrm{~mm}$, suara yang dihasilkan terdengar lebih gemericik, dan selanjutnya dalam penelitian ini disebut Kondisi 3
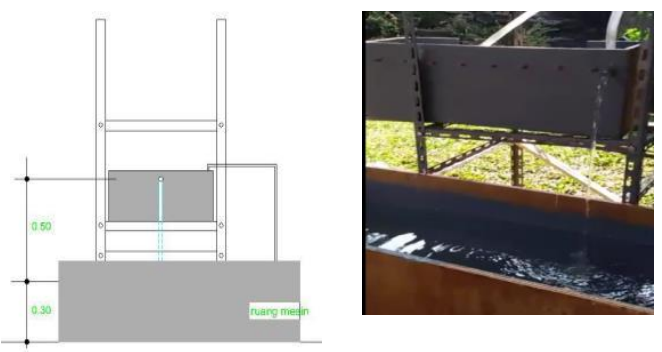

Gambar 3. Kategori III (volume kecil), satu titik tumpahan Sumber: dok.pribadi

Pengukuran masing-masing fitur air dilakukan pada ruangan berukuran $4 \mathrm{~m} \times 3 \mathrm{~m}$ dengan dinding ruangan ditempel styrofoam untuk meminimalkan suara lingkungan luar dan mengurangi gema yang ditimbulkan oleh masing-masing fitur air. Selanjutnya bunyi masing-masing fitur direkam selama 10 menit dengan mikrofon ECM 8000 Behringer dan recorder Zoom H6. Suara hasil rekaman diolah melalui software Audacity untuk menghasilkan rekaman yang akan dijadikan stimulus dalam uji subyektif.. Dari hasil pengukuran dapat dilihat perbedaan karakter dan warna dari ketiga Kondisi fitur air, seperti yang ditunjukkan diagram spektrum dibawah ini:

Berikut adalah hasil pengolahan data dari relatif ke absolut

Tabel 1 Perbandingan level enegi masing-masing Kondis pada frekuensi yang berbeda.

Sumber: dok.pribadi

\begin{tabular}{|r|r|r|r|}
\hline & & & \\
\hline & Kondisi-1 & Kondisi-2 & Kondisi-3 \\
\hline OVERALL & 69,3 & 73,8 & 64,2 \\
\hline & & & \\
\hline
\end{tabular}

Gambar 7. Grafik Perbandingan level energy masing-masing Kondisi pada frekuensi yang berbeda (low-med-high).

Sumber: dok.pribadi

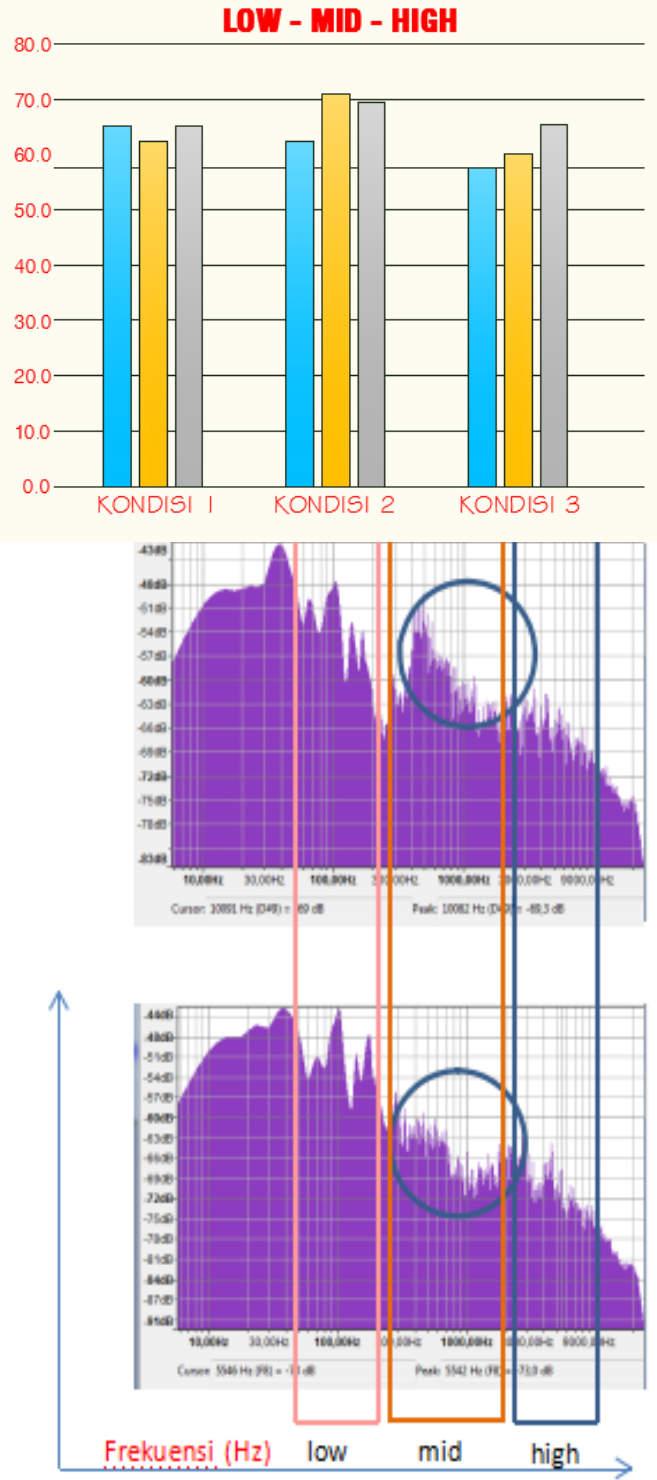

Pada frekuensi rendah (100-400 Hz), kondisi 1 memilidki level energi atau tingkat tekanan suara $65,1 \mathrm{~dB}$, kondisi $2=62,3 \mathrm{~dB}$, dan kondisi $3=57,6 \mathrm{~dB}$

Pada frekuensi menengah (500-1600 $\mathrm{Hz}$ ), kondisi 1 memiliki level energi atau tingkat tekanan suara $62,4 \mathrm{~dB}$, kondisi $2=$ $70,9 \mathrm{~dB}$, dan kondisi $3=56,6 \mathrm{~dB}$. 
Pada frekuensi tinggi (2000-8000 Hz), kondisi 1 memiliki level energi atau tingkat tekanan suara $65,0 \mathrm{~dB}$, kondisi $2=69,4 \mathrm{~dB}$, dan kondisi $3=61,6 \mathrm{~dB}$

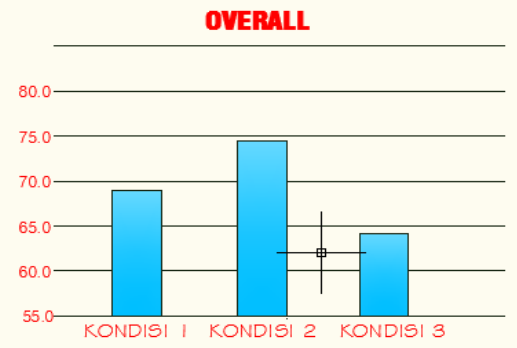

Gambar 7. Grafik Perbandingan level enegy pada semua frekuensi. Sumber: dok.pribadi

Tabel 2. Perbandingan level enegy semua frekuens Sumber: dok.pribadi

\begin{tabular}{|l|r|r|r|}
\hline & kondisi & kondisi 2 & kondisi 3 \\
\hline LOW (100-400 & 65,1 & 62,3 & 57,6 \\
\hline MID (500-1600) & 62,4 & 70,9 & 56,6 \\
\hline HIGH (2000- & 65,0 & 69,4 & 61,6 \\
\hline $8000 \mathrm{~Hz})$ & & & \\
\hline
\end{tabular}

Pada semua frekuensi, level energi atau tingkaT tekanan suara masing-masing kondisi tercatat: kondisi $1=69,3 \mathrm{~dB}$, kondisi $2=73,8$ $\mathrm{dB}$, dan kondisi $3=64,2 \mathrm{~dB}$.

\subsection{Menguji Stimulus}

Melalui uji listening, stimulus diujikan pada 30 responden yang terdiri dari 18 laki-laki dan 12 perempuan dengan rentang umur $30 \quad-45$ tahun. 10 orang berada pada kisaran umur 30 35 tahun, 15 orang berada pada umur $35-40$ tahun dan 5 orang pada kisaran umur $40-45$ tahun. Pencahayaan dan hawa ruagan diatur sedemikian rupa. Untuk meminimalisir suara suara luar, uji listening menggunakan headseat (merek Sony XB450) dan responden disarankan memejamkan mata agar lebih fokus.

\subsection{Metode Pengukuran}

Data yang diukur terkait respon persepsi dan respon emosi diambil melalui kuisioner dengan semantik differensial, yaitu menggunakan dua kata sifat yang berlawanan. Pengukuran respon persepsi dikaitkan dengan atribut fisik berupa kualitas bunyi air (ketajaman, kasar- halus, kecepatan yang dikaitkan dengan deras atau pelan) dan variasi bunyi yang yang dikaitkan dengan konstan atau bervariasinya bunyi. Sementara penilaian terhadap respon emosi dikaitkan dengan dampak ketenangan, rileks, alami, familiar, kesegaran, senang dan tegang (Calarco dan Galbrun, 2014)

Tabel 3. contoh penggalan semantik diferencial dalam pengukuran persepsi

\begin{tabular}{|r|l|c|c|c|c|c|l|}
\hline & & S & A & A & AS & S & \\
\hline & & 1 & 2 & 3 & 4 & 5 & \\
\hline 1 & Buatan & & & & & & Alami \\
\hline 2 & Asing & & & & & & Familiar \\
\hline 3 & Tidak & & & & & & Menarik \\
\hline 4 & Melelahkan & & & & & & Menyegarkan \\
\hline
\end{tabular}

Skor 1 untuk menyatakan setuju terhadap kata sifat di kelompok kiri, skor 2 sebagai pernyataan agak setuju pada kelompok kiri, skor 3 sebagai pernyataan ragu-ragu, skor 4 sebagai pernyataan agak setuju terhadap kata sifat di kelompok kanan, dan skor 5 sebagai pernyataan setuju pada kata sifat di kelompok kanan.

Pada saat uji listening, setiap Kondisi diperdengarkan dalam durasi 5 menit, setelah itu responden dipersilahkan mengisi kuisioner persepsi yang mereka rasakan, rata-rata responden sudah dapat merespon pada menit ke-3 dengan mengisi kuisioner yang telah disiapkan. Untuk setiap satu uji listening dilakukan break 5 menit untuk memulihkan atau menormalisasi dari persepsi sebelumnya.

\section{Hasil Penelitian}

Data yang diperoleh diolah melalui serangkaian uji Anova melalui software SPSS - penilaian terhadap respon persepsi dapat dilihat dari grafik estimasi dibawah ini:

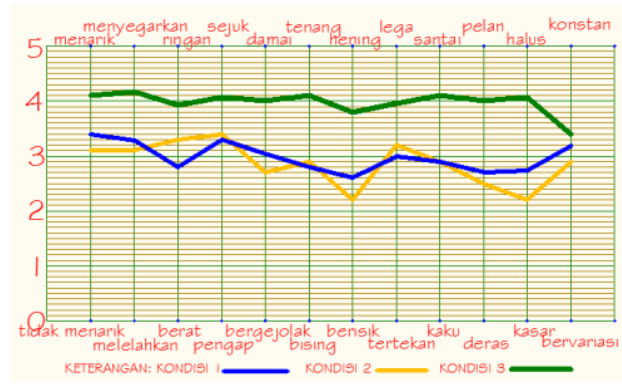

Kondisi 3 berada diatas batas netral (skala 3 ), sementara kondisi 1 dan 2 berada disekitar garis netral. Diagram diatas menunjukkan 
bahwa kondisi 3 ( tumpahan 1 titik ) mendapat respon paling tinggi atau respon paling positif. Selanjutnya penilalian terhadap respon emosi dapat dilihat dari grafik estimasi dibawah ini:

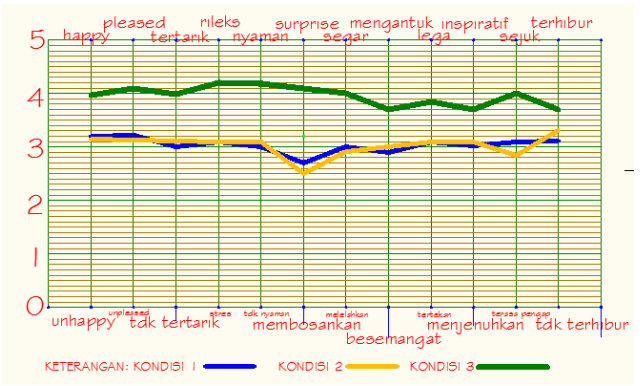

Kondisi 3 berada diatas garis batas netral (skala 3), sementara kondisi 1 dan 2 berada disekitar garis netral. Diagram diatas menunjukkan bahwa kondisi 3 (tumpahan 1 titik) mendapat respon paling tinggi atau respon paling positif, sedangkan kondisi 1 (tumpahan lebar) mendapat respon paling rendah atau respon paling negatif.

\section{Diskusi}

Hasil perangkingan / leveling terhadap ketiga kondisi diuraikan dari respon paling positif ke respon paling negatif, yaitu:

- Untuk respon persepsi; kondisi 3 kondisi 1 - kondisi 2

- Untuk respon emosi; kondisi 3 kondisi 2 - kondisi 1.

Kondisi 3 memiliki bentuk tumpahan satu titik sebagai perwakilan dari volume tumpahan kecil berada pada level diatas garis rata-rata, Kondisi 2 memiliki bentuk tumpahan beberapa titik sebagai perwakilan dari volume sedang, sementara Kondisi 1 dengan bentuk tumpahan melebar sebagai perwakilan volume tumpahan besar rata rata berada disekitar garis batas ( skala 3 )

Pada frekuensi rendah, kondisi 3 memiliki level energi atau tingkat tekanan suara paling rendah, sedangkan kondisi 1 memiliki level energi atau tingkat tekanan suara paling tinggi. Sementara pada frekuensi menengah dan tinggi Kondisi 2 memiliki tingkat tekanan suara paling tinggi.

\section{Efek Interaksi antar Kondisi}

Kondisi 1 dibandingkan dengan kondisi 2

Kedua jenis respon (persepsi dan emosi) memperlihatkan hasil yang sama yaitu tidak signifikan. Setelah responden merespon kondisi 1 kemudian berpindah merespon kondisi 2, terjadi penurunan nilai respon. Bunyi bervariasi yang dihasilkan dari tumpahan beberapa titik cenderung dinilai bergejolak, bising, berisik yang mempengaruhi emosi responden pada perasaan yang tidak nyaman atau kurang menyenangkan. Walaupun diseting pada ketinggian yang sama, bunyi pada Kondisi 2 dirasakan lebih tajam dan cenderung memiliki tekanan lebih tinggi dari variasi gemericik tumpahannya.

\section{Kondisi 1 dibandingkan Kondisi 3}

Kedua jenis respon (persepsi dan emosi) memperlihatkan hasil yang sama, yaitu siginfikan. Kondisi 1 memiliki bentuk tumpahan melebar dan solid dengan debit air tumpahannya besar, sedangkan kondisi 3 memiliki bentuk tumpahan pada satu titik. Setelah responden merespon kondisi 1 kemudian berpindah merespon kondisi 3 terjadi penaikkan nilai respon. Responden merespon positif bunyi air yang dihasilkan dengan bentuk tumpahan satu titik. Volume tumpahan dengan debit air yang kecil cenderung menjadi daya tarik yang dipersepsikan ringan, sejuk, damai lebih halus yang cenderung memberi perasaan nyaman, rileks dan lega. Kondisi 3 memiliki tekanan suara lebih rendah, gelombang dan gelembung air yang dihasilkan yaitu menjadi lebih sedikit dan lebih tenang yang berdampak pada ketajaman suara yang dihasilkan menjadi lebih rendah.

\section{Kondisi 2 dibandingkan Kondisi 3}

Respon persepsi dan emosi menunjukkan nilai yang signifikan, artinya setelah merespon kondisi 2 dan berpindah pada kondisi 3 terjadi penaikan nilai respon. Kondisi 2 berupa tumpahan dengan beberapa titik menghasilkan suara yang lebih bervariasi akibat gelombang dan gelembung yang dihasilkan lebih banyak dan bervariasi sedangkan kondis 3 memiliki tumpahan satu titik dan memiliki tekanan suara lebih rendah, cenderung direspon lebih positif dari karakter air dan dampak emosi yang ditimbulkan. Respon positif untuk persepsi dikaitkan dengan kesan ringan menyejukkan, damai, hening dan lebih halus. Demikian juga respon terhadap emosi mendapat respon yang baik, terkait perasaan senang, nyaman, segar, lebih lega, menjadi rileks dan bahkan mengantuk. 


\section{Kesimpulan}

Dari ketiga fitur air yang diujikan dalam penelitian ini, fitur yang mendapat respon paling positif adalah Kondisi 3. Ada kecenderungan semakin kecil volume air dalam setiap tumpahannya akan menghasilkan tekanan suara atau level energi yang lebih kecil yang membawa pengaruh pada karakteristik air. Permukaan air bak penampungan akan lebih tenang, gelombang dan gelembung yang dihasilkan lebih halus yang membawa pengaruh terhadap respon persepsi dan emosi.

Tentunya hasil dan simpulan dari penelitian ini belumlah sempurna mengingat metode pengukurannya didapat dari angket kuisioner. Mungkin untuk penellitian lanjutan metode pengukurannya bisa melibatkan pengukuran yang lebih detail, seperti pengukuran denyut jantung ataupun uji lab seperti EEG, sehingga nilai akurasinya lebih mendekati benar. Semoga penelitian ini dapat menjadi tambahan pengetahuan bagi akademisi dan praktisi dalam mehadirkan atau memanipulasi elemen air ke dalam desain interior.

\section{Daftar Pustaka}

Arsyad, S. (2000): Konservasi Tanah dan Air, Bandung-Penerbit IPB (IPBPress).

Booth, Norman K (1990): Basic element of landscape architectural design, WavelandProspect Height.

Chaplin, J.P (2006):Kamus Lengkap Psikologi, Jakarta-Publisher

Goldstein, E. Brucc (2010): Sensation and Perception, Eight Edition, United States of America - Wadsworth

Setiawan, Hariyadi B.(1996): Arsitektur Lingkungan dan Prilaku, YogyakartaDirektorat Jendral Pendidikan Tinggi

Sugiyono,(2011): Metode Penilaian Kuantitatif, Kualitatif dan $R$ \& $O$, Bandung-Alfabeta

Syukur (2011): Beragam cara terhapy; gangguan sehari-hari, Yogyakarta-Duva Press.

Wylson, Anthony (1986):Aquatecture: Architecture and water, The University of California-Publiser Architectural Press.

Calarco, F.M.A., \& Galbrun, L. (2014):
Semantic assesment of water features used over roadtraffic noise, Paper presented at Forum Acusticum 2014, Krakow, Poland

G. Watts, R. Pheasant, K Horoshenkov, L. Ragonesi, (2009): Measurement andsubjective assessment of water generated sounds, Acta Acust. United with Acust. 95, 1032-1039

J. Kang, Taylor dan Francis(2007): Urbarn Sound Environment, New York

J.Y. Jeon, P.J. Lee, J.You, J. Kang, (2010): Perpectual assessment of quality of urbansoundscapes with combined noise sources and water sounds, J. Acoust. Soc. Am. 127(3), 1357-1366)

J.Y. Jeon , P.J. Lee, J. You, dan J. Kang (2012): Acoustical characteristics of water sounds for soundscapes enhancement in urban open spaces, J. Acoust. Soc. Am. 131 2101-2109.

Lunden, peter \& Nilsson, mats (2015): Perceptual and phsycoacustik, Faculty of Social Sciences, Departement of Psicoloagy

L. Galbrun dan T.t. Ali(2013):Acoustical and perpectual assesment of water sounds and their use over road traffic noise, J. Acoust. Soc. Am. 133 227-237

L. Galbrun, T.T. (2011): Acoustic design of water feautures forthe built environment, Proceeding of the Institute of Acoustics, 33(4), 112-119, Acoustics 2011, Glasgow, 14-15 September

Laurent Galbrun, Tahrir Ali (2012): Perpectual assesment of water sounds for road traffic noise masking, Societe Francaise d'Acoustique, Acoustics, Apr 2012, Nantes, Fauce (hal 00811210)

Maufeld dan Heyer (2003): Colour Perseption: Mind and the physical world, Oxford University Press. 